\title{
[REVIEW]
}

\section{Innate Immunity in Ticks: A review}

\author{
DeMar TAYLOR* \\ Graduate School of Life and Environmental Sciences, University of Tsukuba, Tsukuba, Ibaraki 305- \\ 8572, Japan
}

(Received 5 October 2006; Accepted 14 November 2006)

\begin{abstract}
Ticks transmit more different kinds of pathogenic organisms than any other hematophagous arthropod. This paper attempts to review the literature available on the cell-mediated and humoral responses of ticks. The cell-mediated defense responses by invertebrates are simpler than vertebrates, but are effective as a second line of defense against invasion by microorganisms. Hemocytes play a major role in this immune response through phagocytosis, nodule formation and encapsulation of invading foreign materials. These mechanisms appear to function in both soft and hard ticks. Humoral immune responses consist of three main types; humoral encapsulation, hemagglutination and production of antimicrobial proteins. Humoral encapsulation is elicited by the prophenoloxidase activating system and has only been shown to function in the soft tick Ornithodoros moubata. However, recent studies show the hard ticks also have prophenoloxidase activating cofactors indicating humoral encapsulation also functions in these ticks. Tick lectins function in hemagglutination of various microorganisms in both soft and hard ticks and also appear to function as recognition molecules of nonself and possibly in the transmission of pathogenic microorganisms. Ticks also have numerous antimicrobial proteins that can attack the invading microorganisms. Lysozymes have been shown to have bactericidal effects in several tick species and work in concert with other antimicrobial peptides to kill invaders. Cystatins, classic cysteine protease inhibitors, have recently been shown to function in innate immune responses of ticks. Hemoglobin fragments have antimicrobial activity in the midgut of ticks. Defensins show expression up-regulated by blood feeding and are effective antimicrobial agents with some differences between soft and hard ticks. Other novel antimicrobial peptides have been isolated from various species of soft and hard ticks, but their functions remain to be elucidated. Understanding these innate immune mechanisms in ticks is essential to develop strategies for reducing the transmission of diseases to man and animals.
\end{abstract}

Key words: cell-mediated immunity, humoral immunity, ticks, phagocytosis, hemocytes, encapsulation, lectins, lysozyme, defensin, hemoglobin fragments

\section{INTRODUCTION}

Ticks are important vectors of arthropod transmitted diseases. The diversity of pathogenic organisms transmitted by ticks exceeds that found in all other hematophagous arthropods. Ticks obtain blood for development and reproduction from vertebrate hosts and in the process of feeding become infected with and transmit a wide range of microorganisms

* Corresponding author: e-mail: taylor@sakura.cc.tsukuba.ac.jp; Tel/Fax: +81-29-853-4806 
including protozoans, viruses, bacteria, rickettsia and nematodes (Sonenshine, 1993). Pathogens are also often transtadially and transovarially transmitted contributing to the complexity and importance of ticks in pathogen proliferation and disease transmission. Ticks of different species transmit different microorganisms. Understanding the innate immune mechanisms of different ticks species may help to answer questions as to why some microorganisms are transmitted and others not and why some ticks are vector competent and others are not.

Invertebrates defend themselves from infection with an innate immune system without antibodies and memory cells. The integument and gut are the first lines of defense. A complex interaction of cellular and humoral reactions occurs when invaders get past these barriers. These innate immune reactions are nonspecific responses consisting of cellular responses such as phagocytosis, nodule formation and encapsulation, and humoral responses such as humoral encapsulation, hemagglutination and antimicrobial proteins. These innate immune mechanisms have been extensively studied from various aspects in insects and there are numerous review articles describing this research (Bangham et al., 2006; Gillespie et al., 1997; Hoffmann and Hoffmann, 1990; Hultmark, 1993; Lackie, 1988; Lehane et al., 2004; Millar and Ratcliffe, 1994; Sadd and Schmid-Hempel, 2006; Schmid-Hempel, 2005; Vilmos and Kurucz, 1998). Despite their importance as vectors of disease the immune mechanisms of ticks have only recently attracted the attention of researchers so there is much less known about the innate immunity of ticks. This paper is an attempt to present what is now known about the tick immune system. I review the literature available on cell-mediated and humoral defense responses in both soft and hard ticks. First, I briefly describe the cellmediated defense response as understood from research in other organisms and then specifically review the work that has been done on tick phagocytosis, hemocytes, nodule formation and encapsulation. After which the humoral defense response is briefly discussed and then humoral encapsulation, hemagglutination and antimicrobial peptides in ticks reviewed. Discussions on lysozymes, cystatins, defensins and other antimicrobial peptides make up the largest portion of the section on humoral defense mechanisms.

\section{CELL-MEDIATED DEFENSE RESPONSES}

The cell-mediated defense system of invertebrates is much simpler than vertebrates because they lack an antigen-antibody complex and memory cells. Pathak (1993) has reviewed earlier studies on insect innate immunity. Hemocytes selectively increase with pathogen infection and play a key role in cellular defense by three main mechanisms; phagocytosis, nodule formation and encapsulation. Phagocytosis is the process of consuming invaders to remove them from circulation and is confined to specialized cells. In insects, certain foreign particles cause a phagocytic reaction whereas others do not (Götz and Boman, 1985). Nodule formation is where the invaders are entrapped in a coagulum of granular cells surrounded by a sheath of blood cells that may or may not undergo melanization. This is usually a reaction by the hemocytes to large numbers of bacteria, fungi, protozoa or suspensions of living and non-living particles (Götz, 1986). Encapsulation involves enclosure of nodules or foreign invaders larger than the hemocytes in several 
layers of cells to isolate them from active circulation (Götz and Boman, 1985; Götz, 1986). The roles of the hemocytes in these defense mechanisms have been studied extensively in insects and reviewed by several workers (Gillespie et al., 1997; Götz, 1986; Millar and Ratcliffe, 1994; Pathak, 1993; Ratcliffe and Rowley, 1979; Ratcliffe, 1982; Rowley and Ratcliffe, 1981). However, there are few studies on the cell-mediated defense mechanisms and the roles of hemocytes in ticks. Research done to date on cell-mediated defense mechanisms of ticks is briefly reviewed below.

\subsection{Phagocytosis and Tick Hemocytes}

The first reports of phagocytosis in ticks were by Machel (1977) and Podboronov et al. (1982). Subsequent studies indicated that ticks use hemocytes to remove pathogenic invaders from the hemolymph, similar to insects (Gupta, 1991). Bázliková et al. (1984) showed in the hard tick Hyalomma dromedarii that hemocytes phagocytized intracoelomally inoculated Coxilla burnetii whether the parasites were alive or dead. Kuhn (1996) reported that hemocytes were induced to accumulate by wounding with a nonsterile puncture and a blood meal induced the proliferation of the hemocytes. Johns et al. (2000, 2001a) showed that hemocytes cleared Escherihica coli from the hemolymph of Dermacentor variabilis. Loosova et al. (2001) showed that tick hemocytes actively phagocytized pathogenic yeast cells.

Three basic types of hemocytes have been described in both hard and soft ticks (Inoue et al., 2001; Kuhn and Haug, 1994). However, it has been reported that only the plasmatocytes are phagocytic in hard ticks (Brinton and Burgdorfer, 1971; Kuhn and Haug, 1994). Pereira et al. (2001) detected two types of hemocytes, plasmatocytes and granulocytes, in Boophilus microplus and showed the plasmatocytes were the most abundant and responsible for in vivo phagocytosis. Subsequently, Kuhn et al. (1994) showed the involvement of granular hemocytes as well as plasmatocytes in phagocytosis of the spirochete Borrelia burgdorferi. Inoue et al. (2001) reported that plasmatocytes and granulocytes were both phagocytic in Ornithodoros moubata. A more recent morphological comparison of hemocytes in Ixodes ricinus and $O$. moubata showed there are two types of phagocytic hemocytes, namely plasmatocytes with a low number of granula and granulocytes that are phagocytic (Borovičková and Hypša, 2005). Silva et al. (2006) showed that both granulocytes and plasmatocytes of $B$. microplus were phagocytic against a Penicillium sp. Phagocytic activity of plasmatocytes and granulocytes was also shown in the soft tick O. moubata (Inoue et al., 2001). In addition, O. moubata has a fourth type of hemocyte that resembles insect spherulocytes and may represent a cell type found only in soft ticks (Borovičková and Hypša, 2005; Kadota et al., 2003). However, spherulocytes appear to not function in phagocytosis. The studies described above strongly indicate the hemocytes, plasmatocytes and granulocytes, play the major role in phagocytic cell-mediated immune responses of both soft and hard ticks.

\subsection{Nodule Formation and Encapsulation}

There have been very few studies on nodule formation and encapsulation in ticks. Ceraul et al. (2002) revealed by direct fluorescence assay that E. coli inoculated into the hemocoel cavity of Dermacentor variabilis aggregated $1 \mathrm{~h}$ post inoculation. Subsequently, aggregated bacteria associated with masses of tissues appeared to form nodules similar to that described 
in other organisms. Eggenberger et al. (1990) showed that encapsulation of implants occurred in D. variabilis. Degranulation of the granulocytes and coagulation of hemolymph began at about $1 \mathrm{hr}$ after implantation and encapsulation was complete by about $6 \mathrm{hr}$, but the plasmatocytes and granulocytes continued to accumulate and form multiple cell layers to complete the capsule at $72 \mathrm{hr}$ after implantation. These two studies suggest that nodule formation and encapsulation are also important in the cell-mediated immune responses of ticks.

\section{HUMORAL RESPONSES}

In addition to the cell-mediated immune responses described above, arthropods exhibit strong humoral responses to work with the cellular responses in the battle against foreign invaders. Three main types of humoral responses, humoral encapsulation, hemagglutination and release of antimicrobial substances have been characterized in arthropods. Humoral encapsulation involves the formation of a melanotic sheath to encase the invader and is normally elicited by a prophenoloxidase casade (Götz, 1986; Götz and Vey, 1986; Vey, 1993). Hemagglutination occurs when specific carbohydrate binding proteins or glycoproteins called lectins bind to the invader and cause aggregation and opsonization to enhance phagocytosis (Ratcliffe and Rowley, 1987; Vasta, 1991; Vasta et al., 1994). Antimicrobial substances are proteins that are synthesized and released to directly kill invading microorganisms (Boman and Hultmark, 1987; Götz and Boman, 1985). The humoral responses of the arthropod immune system have been extensively studied in insects and crustaceans but are less understood in ticks. Therefore, the present knowledge about humoral immune mechanisms in ticks is briefly discussed below.

\subsection{Humoral Encapsulation}

The main characteristics of humoral encapsulation involve the formation of a loose aggregate of melanotic material accumulating around the invader, followed by the aggregate becoming denser until within a few minutes the foreign material is completely entrapped. This encapsulation can be triggered by various stimuli including nematodes, fungi, bacteria, other foreign organisms and foreign materials. Encapsulation is elicited by a prophenoloxidase activating system, in which the first step consists of binding of phenoloxidases and other sticky proteins, and the second step melanization and sclerotization of the invader (Vey, 1993). Although the importance of the prophenoloxidase activating system has been emphasized in arthropod vectors (Ratcliffe et al., 1984; Saul and Sugumaran, 1987), research has focused on crustaceans and insects (Ashida et al., 1990; Gregorio and Ratcliffe, 1991; Hoffman et al., 1996; Söderhäll and Smith, 1986a, 1986b). As far as I can determine, there are only two studies on phenoloxidase activity in ticks. Zhioua et al. (1997) were unable to detect any phenoloxidase activity in Amblyomma americanum, Dermacentor variabilis and Ixodes scapularis even though they were able to detect activity in Galleria mellonella. Therefore they concluded that prophenoloxidase does not act as an opsonin in these ixodid ticks. However, Kadota et al. (2002) was able to detect phenoloxidase activity in 4th instar nymphs of Ornithodoros moubata. The peak levels occurred just before the nymphs molted indicating phenoloxidase may protect the nymphs during the vulnerable 
ecdysial phase. Even though Zhioua et al. (1997) couldn't detect phenoloxidases in hard ticks, it is likely that hard ticks have phenoloxidases because numerous other arthropods have been shown to have the prophenoloxidase activating immune response. In addition, Simser et al. (2004b) were able to isolate a serine proteinase from D. variabilis that has high homology with a number of immune responsive genes including insect prophenoloxidase activating cofactors. Zhioua et al. (1997) may not have been able to detect the low levels of phenoloxidase activity because they used homogenates of adult whole body. Therefore, phenoloxidase activity in the hemolymph of hard ticks needs to be examined, taking into account the instability of phenoloxidases during the analyses (Martin et al., 1995).

\subsection{Hemagglutination}

Hemagglutins or lectins naturally occur in all eukaryotic organisms, many bacterial species and some viruses and are of great importance in the aggregation and opsonization of microorganisms (Ratcliffe and Rowley, 1987; Vasta, 1991; Vasta et al., 1994). In mammals, lectins play an important role as pattern recognition receptors that not only bind broad classes of microorganisms but also activate the complement system (Iwanaga, 2002; Matsushita, 1996; Matsushita et al., 2001; Vasta et al., 1999). Lectins are able to bind and aggregate microorganisms because they are proteins or glycoproteins with one or more sites that bind specific carbohydrates (Goldstein et al., 1980; Peumans and van Damme, 1995). Invertebrate lectins are involved in the processes of cell adhesion, opsonization, phagocytosis and cytolysis (Vasta and Marchalonis, 1983). Membrane bound lectins appear to directly bind to foreign particles whereas humoral hemagglutinins appear to act as opsonic factors that bind to foreign particles and facilitate their uptake by hemocytes (Ratner and Vinson, 1983). Lectins have been extensively studied in invertebrates with the best known invertebrate lectins from the horseshoe crabs and scorpions (Olafsen, 1986, 1996; Vasta and Marchalonis, 1984). Studies on tick lectins have been extensively reviewed by Grubhoffer et al. $(1997,2004)$ and thus are only briefly discussed in this paper.

Tick lectins appear to function in hemagglutination and opsonization of microorganisms as seen in other invertebrates and vertebrates. Agglutinins/lectins with molecular sizes from 30 to $85 \mathrm{kDa}$ have been identified from the hemolymph plasma, hemocytes, gut and salivary glands of several soft and hard tick species. The first reports of tick lectins were by Veres and Grubhoffer (1990) and Grubhoffer et al. (1991) from Ornithodoros tartakovskyi and $O$. tholozani (papillipes). Subsequently, the lectin Dorin M was identified from the plasma of O. moubata and shown to have high hemagglutinating activity (Grubhoffer and Kovar, 1998; Kovar et al., 2000). Recently, Dorin M has been shown to be synthesized in the hemocytes and to be a fibrinogen-related lectin indicating it may function as a non-self recognizing molecule and may also function in pathogen transmission by this vector (Rego et al., 2005, 2006). Kamwendo et al. (1993) described the presence of lectins in the gut and salivary glands of Rhipicephalus appendiculatus. They further showed that sugars that inhibit hemagglutination significantly increased Theileria parva infection rates in the salivary glands indicating an important role for the lectins in hemagglutination (Kamwendo et al., 1995). The midgut of Ixodes ricinus was shown to have hemagglutination activity that was induced by feeding and not detected in starved ticks (Uhlir et al., 1996). Kuhn et al. (1996) 
showed immunoreactivity with poly- and monoclonal antibodies of a lectin from the hemolymph in both types of granular hemocytes, at the basal laminae surrounding the hemocoel, in cells attached to the midgut, in the invaginations of Géné's organ and in granular inclusions of nephrocytes. They concluded hemolymph lectins function as recognition molecules in the immune system of I. ricinus but they also proposed that lectin activity may be involved in the transmission of Borrelia burgdorferi. Recently, Rego et al. (2005) cloned two fibrinogen-related proteins, Ixoderin A and B, that showed significantly high homology to the lectin Dorin $M$ and were primarily expressed in the hemocytes and salivary glands. Lectins appear to be an essential part of non-self recognition, hemagglutination and possibly the transmission of pathogens in both soft and hard ticks.

\subsection{Antimicrobial Proteins}

Another effective humoral response to foreign materials that invade an organism is the production of antimicrobial peptides that can directly attack the invading microorganisms. Antimicrobial peptides appear to be ubiquitous and a part of the innate immune defense response of both prokaryotic and eukaryotic organisms. Extensive research has been done on these peptides in insects and reviewed in a number of recent papers (Bulet et al., 1999; Bulet et al., 2004; Bulet and Stocklin, 2005; Imler and Bulet, 2005; Otvos, 2000). These proteins have extreme diversity in the primary and secondary structures but are able to affect a large number of microorganisms (bacteria, fungi, yeast, virus, nematodes, etc.). They include the lysozymes, cecropins, attacins, defensins, proline-rich peptides, glycine-rich peptides and others. The proline-rich and glycine-rich peptides are predominantly active against Gram-negative bacteria, the defensins against Gram-positive bacteria, and the cecropins against both types. The mode of action of antimicrobial peptides is not fully understood but there appears to be two major modes of action through peptide-lipid interactions and receptor-mediated recognition processes. Antimicrobial peptides also play an important role in the humoral responses of ticks but these roles are still not well known. The research on antimicrobial peptides conducted to date in ticks is briefly outlined below.

\subsubsection{Lysozymes}

Lysozymes are ubiquitously expressed in most animal species and act as enzymes that lyse bacteria by cleaving the $\beta-1,4$ glycosidic bonds in the peptidoglycan cell wall (Jollès and Jollès, 1984; Qasba and Kumar, 1997). Lysozymes are normally present in the hemolymph of insects and induced when the insect becomes infected. They were the first humoral antibacterial factor studied in insects and numerous studies have been conducted in insects to understand the importance and mechanisms of these enzymes as related to the immune response. Kaaya (1993) and Hultmark (1996) review research on insect lysozymes.

Digestion occurs intracellularly in the midgut epithelial cells of ticks (Sonenshine, 1993) and the blood meal is stored in the midgut until nutrients are needed. Therefore, the gut provides an ideal environment for the multiplication of microbes ingested during feeding (Munderloh and Kurtti, 1995). Podborornov and co-workers were the first to systematically study the characteristics and antibacterial activity of lysozymes in ticks. They compared the responses to a number of bacterial species in homogenates of several tick species including Alveonasus lahorensis, Ornithodoros papillipes, O. moubata, Hyalomma asiaticum and Ixodes persulcatus and published numerous papers in Russian (English review see 
Podboronov, 1991). The lysozymes from O. moubata, O. papillipes and A. lahorensis had the greatest bactericidal effects whereas those from $H$. asiaticum had the lowest activity. Johns et al. (1998) showed a protein co-migrating with human lysozyme in the hemolymph of Dermacentor variabilis that increased greatly in ticks infected with Bacillus subtilis. Hemocoelic inoculations of D. variabilis with Borrelia burgdorferi also induced upregulation of a lysozyme-like peptide (John et al., 2000). Simser et al. (2004a) identified and characterized a c-type lysozyme from the hemocytes of $D$. variabilis and an embryonic derived cell line of $D$. andersoni at the molecular level and demonstrated the involvement of these tick lysozymes in innate immunity. Sonenshine et al. (2005) reported a lysozyme transcript in the midgut cells of $D$. variabilis but could not detect the protein. In addition, they reported that $B$. burgdorferi spirochetes were not lysed in the midgut lumen indicating lysozyme was not effective in the midgut. Kopáček et al. (1999) purified and characterized a lysozyme from the gut of $O$. moubata that displayed high activity against bacteria. Subsequently, Grunclová et al. (2003) sequenced and analyzed this lysozyme from the gut of O. moubata. They showed that the lysozyme is significantly up-regulated at the transcriptional level after a blood meal but could not clearly establish whether this is a response to bacterial infection. They suggested this lysozyme is an enzyme with both immune and digestive characteristics. Simser et al. (2004a) showed that D. variabilis responded to bacterial challenge with induction of lysozyme independently of mechanical injury and digestive processes. Lysozymes have been shown to synergize the effects of antimicrobial peptides on B. borrelia and Rickettsia monacensis and R. peacockii (Baldridge et al., 2005; Johns et al., 2001a). The results of the above studies indicate lysozymes play an important role in the innate immune responses of both soft and hard ticks. However, there may be some differences in the lysozyme functions in soft and hard ticks as indicated by the results that lysozymes were active in the gut of soft ticks but not the gut of hard ticks. In addition, lysozymes were up-regulated in the hemolymph and hemocytes of hard ticks but have not been investigated in soft ticks. Further work is needed to clarify these differences and the mechanisms and functions of lysozymes in soft and hard ticks.

\subsubsection{Cystatins}

Cystatins are reversible inhibitors of papain-like cysteine proteases that are found in many plants and animals. Traditionally, they were the focus of much research in vertebrates because they function to mediate proteolysis in the lysosome and were thought important in preventing damage caused by cysteine proteases released outside the lysosome. Recent studies have shown cystatins have numerous specific roles in vertebrates including antigen presentation (Honey and Rudensky, 2003), immune system development (Lombardi et al., 2005), epidermal homeostasis (Reinheckel et al., 2005), degradation of the extracellular matrix and neutrophil chemotaxis during inflammation (Reddy et al., 1995; ServeauAvesque et al., 2006), apotosis (Wille et al., 2004) proliferation of malignant cells and their invasion into healthy tissues (Joyce et al., 2004; Nomura and Katunuma, 2005). Cystatins are also implicated to regulate protein turnover in plants and protect plants against insect and pathogen invasion (Turk and Bode, 1991). Mammalian cystatin C has also been indicated in the defense against pathogen invasion (Olsson et al., 1999). Filarial cystatins are important in the balance of the host-parasite immune relationship (Schierack et al., 2003) and cystatins 
in parsitoids appear to play a role in host physiological deregulation by inhibiting the host proteases (Espagne et al., 2005). Cystatins have only recently been found in ticks (Karim et al., 2005; Kotsyfakis et al., 2006; Lima et al., 2006; Valenzuela et al., 2002; Zhou et al., 2006). Valenzuela et al. (2002) first identified cystatin in a salivary gland cDNA library of Ixodes scapularis. Subsequently, Kotsyfakis et al. (2006) showed that a cystatin, Sialostatin L, from the above cDNA library of Ixodes scapularis was present in the saliva and actively affected host proteolytic activity at sites of infestation. Sialostatin L displayed an antiinflammatory role and inhibition of cytotoxic $\mathrm{T}$ lymphocyte proliferation in the host, thus contributing to successful feeding and pathogen transmission. Karim et al. (2005) also showed that RNAi-mediated silencing of cystatin significantly reduced the ability of Amblyomma americanum ticks to successfully feed and concluded that these ticks evade the host immune response by secreting cystatin to disrupt normal antigen processing and presenting. Cystatins have also been shown to function as defense proteins in plants and mammals (Olsson et al., 1999; Turk and Bode, 1991), to have antimicrobial activity against Gram-negative bacteria in the horseshoe crab, Tachypleus tridentatus (Agarwala et al., 1996), and to function as defense proteins against invading pathogens and parasites that use cysteine proteases to enter their host in the silk moth, Bombyx mori (Yamamoto et al., 1999). However, it wasn't until this year that cystatins were shown to be expressed in tissues other than the salivary glands of ticks (Lima et al., 2006; Zhou et al., 2006) and play a role in the innate immune response of ticks (Zhou et al., 2006). Lima et al. (2006) showed cystatin genes were expressed in the fat body and ovary, and protein bands were present in the fat body, ovary and salivary glands of Boophilus microplus. They suggested a possible role for cystatin in the ovary but this role remains unknown. Zhou et al. (2006) identified a novel cystatin with inhibitory activity against cysteine proteases from the midgut and hemocytes of Haemaphysalis longicornis. Blood feeding and LPS injection increased cystatin expression in the midgut of adult ticks, whereas Babesis gibsoni infection increased cystatin expression in larval ticks. The up-regulation of cystatin in the midgut of $H$. longicornis and significant inhibition of $B$. bovis growth in culture by recombinant cystatin indicate the cystatins are important in the innate immune response of these ticks. As of yet there are no reports on cystatins in the soft ticks. In addition to the role of cystatins in the suppression of the host immune system, recent research indicates they also play an important role in the humoral response against pathogens in ticks. Much work remains to be done to determine the importance of cystatins in the innate immune response of ticks, but these molecules will likely provide an excellent tool for development of potential pharmaceutical applications and tick vaccines.

\subsubsection{Hemoglobin Fragments}

As briefly discussed above the tick midgut is a highly favorable environment for the growth of microorganisms ingested by blood feeding because of the absence of proteolytic enzymes in the midgut (Sonenshine, 1993). Antimicrobial peptides are essential in the humoral immune response and studies on lysozymes cannot fully explain the antimicrobial responses to infection in ticks. Hemoglobin is important as a carrier of oxygen but it has recently been shown to be a source of other bioactive peptides (Ivanov et al., 1997). Parish et al. (2001) showed human $\alpha$ - and $\beta$-hemoglobin fragments have antibacterial and 
antifungal activities. In addition Froidevausx et al. (2001) showed that the bovine $\alpha$ hemoglobin has antibacterial activity against Micrococcus luteus. Fogaça et al. (1999) investigated antimicrobial activity in the gut contents of noninfected ticks and subsequently purified a peptide with antibacterial activity from the gut contents of Boophilus microplus. The amino acid sequence revealed this peptide was a fragment of the bovine $\alpha$-hemoglobin and a synthetic peptide identical to the native peptide showed antimicrobial activity against Gram-positive bacteria and fungi at micromolar concentrations (Fogaça et al., 1999). Sforca et al. (2005) upon further investigation showed that this $\alpha$-hemoglobin fragment functions by disrupting the bacterial membrane. Nakajima et al. (2003b) also reported the purification of two rabbit $\alpha$-hemoglobin fragments from the midgut lumen of Ornithodoros moubata. These fragments showed antibacterial activity against Staphylococcus aureus. Sonenshine et al. (2005) reported that fragments of rabbit $\alpha$-, $\beta$ - and $\gamma$-hemoglobins in the midguts of Dermacentor variabilis females have antibacterial activity. These results indicate that both soft and hard ticks use host hemoglobin fragments as antimicrobial defense mechanisms. Further studies are needed to clarify whether hemoglobin fragments are also present in the hemolymph and the mechanisms by which they are made and function in the innate immune responses of ticks.

\subsubsection{Defensins}

Defensins are the most widespread group of antimicrobial peptides in invertebrates with the majority reported from insects. However, insect defensin-like molecules have been found in scorpions (Cociancich et al., 1993; Ehret-Sabatier et al., 1996) and mollusks (Charlet et al., 1996; Hubert et al., 1996) as well as ticks. Although work on antimicrobial peptides in ticks is still in its infancy, defensins are also the most studied antimicrobial peptides in ticks. Defensins are cyclic antimicrobial peptides containing six cysteine residues with the same cysteine pairing, Cys1-Cys4, Cys2-Cys5, Cys3-Cys6, in insects. They are commonly $4 \mathrm{kDa}$ peptides induced by anti-gram-positive bacteria with a high affinity for the major phospholipids of bacteria (Gillespie et al., 1997).

The first report of defensin in ticks was a partial amino acid sequence with $100 \%$ homology to a scorpion $4 \mathrm{kDa}$ defensin purified from the hemolymph of Ornithodoros moubata (van der Goes van Naters-Yasui et al., 2000). Subsequently, the full length sequences of four defensin isoforms were obtained (Nakajima et al., 2001, 2002b). RT-PCR analyses of these defensin genes revealed they are expressed in all stages from eggs to adults and appear to be constitutively expressed. Bacterial injection showed little or no upregulation of defensin mRNA in tick whole body but strong up-regulation in specific tissues. Defensin up-regulation was induced by injection of Gram-positive bacteria, and bacterial cell components in the midgut as well as the hemolymph plasma and granulocytes (Nakajima et al., 2003c). The strongest up-regulation was observed in the midgut with weak up-regulation in other tissues. Blood feeding has been shown to strongly up-regulate the expression of these four defensin genes especially in the midgut (Nakajima et al., 2001, 2002a, 2002b, 2003c). This is different from many insects in which defensin genes are induced by bacterial infection and the fat body and hemocytes are the main sites of expression. Nakajima et al. (2002a, 2005) also revealed that there is an increase in defensin peptide concentration following blood feeding and the four defensins are secreted into the 
midgut lumen to function in midgut defense in O. moubata. Nakajima et al. (2003a) reported that the four Ornithodoros defensins discussed above have strong antibacterial activity against Gram-positive bacteria including resistant strains such as MRSA, low hemolytic activity and the ability to kill bacteria by lysis of the cytoplasmic membrane. Matsuo et al. (2004) showed expression and slight up-regulation of defensin in the midgut of O. moubata adult females after ingestion of $E$. coli.

Immediately following Nakajima's report of the first two isoforms of defensin in $O$. moubata, Professor Sonenshine's group at Old Dominion University reported the identification of a defensin from the hemolymph of the American dog tick Dermacentor variabilis (Johns et al., 2001b). This defensin showed $83 \%$ similarity to a defensin from a scorpion and was not effective against Borrelia burgdorferi unless combined with lysozyme. Sonenshine et al. (2002) detected bands that co-migrated with the defensin band identified by John et al. (2001b) in hemolymph of D. variabilis challenged with B. burgdorferi but not in hemolymph of ticks challenged with Bacillus subtilis and E. coli. In the same study, Sonenshine et al. (2002) showed that the response of the midgut to challenge with the same three species of bacteria (B. subtilis and E. coli as well as B. burgdorferi) induced the expression of defensin-like peptides. They concluded that responses to infection are different in the midgut and hemolymph and this difference may explain why spirochetes remain intact in the midgut but are rapidly lysed in the hemolymph. Ceraul et al. (2003) reported the identification of a defensin expressed in the hemocytes of $D$. variabilis and suggested that defensin is stored in the hemocytes and released into the hemolymph when stimulated by bacterial infection. In a more recent study Sonenshine et al. (2005) reported that challenge with different bacteria, peptidoglycan, bacterial wall components, hemoglobin, heme or serum did not lead to defensin expression. Instead they identified the hemoglobin fragments discussed above and concluded the antimicrobial activity in the midgut of D. variabilis is primarily related to the host-derived hemoglobin fragments rather than defensin and other antimicrobial peptides.

Defensin and defensin-like proteins have been identified and analyzed from other tick species. Fogaça et al. (2004) isolated a $4285 \mathrm{Da}$ defensin from hemocytes of Boophilus microplus that showed a similarity of $65 \%$ to the $O$. moubata defensins. The hemocytes and the fat body were shown to be the major sites of expression of this defensin, which is different than O. moubata showing the main expression in the midgut. Lai et al. (2004a) identified two defensin-like proteins, named Amblyomma defensin peptide 1 and Amblyomma defensin peptide 2, from the hemolymph of Amblyomma hebraeum. The expression of peptide 1 was up-regulated during the first 4 days post-feeding. Peptide 2 showed antibacterial activity against both Gram-positive and Gram-negative bacteria. Peptide 2 was shown to have a net negative charge, which is unique when compared to all other reported defensins that have a net positive charge to interact with the negative bacterial membranes. Therefore, it is difficult to explain the antibacterial mechanism of this defensin, but the discovery of non-cationic defensin-like peptides indicates the antimicrobial mechanisms are more complex than before thought. By subtractive hybridization Rudenko et al. (2005) showed that expression of a defensin gene is induced in Ixodes ricinus after a blood meal. Hynes et al. (2005) identified a defensin gene from tissues of female Ixodes scapularis ticks 
and RT-PCR indicated the gene is expressed in the midgut, hemocytes and fat body. However, this defensin was not detected in the hemolymph after injection with B. burgdorferi, B. subtilis or E. coli and it is not known why this difference from $D$. variabilis occurs in I. scapularis. They suggested that it may be due to differences in signals or receptors and indicate that differences in receptors and accessory proteins may explain differences in the microorganisms transmitted by tick species. The above results clearly show the importance of defensins in the immune responses of both soft and hard ticks. They also show that there are some differences in the responses between tick species and these differences may result in the transmission of disease in some species and not others. Although, we have a good start for understanding the mechanisms by which defensins function much remains to be clarified. Further studies at the molecular level, protein level and organismal level are needed to understand these mechanisms.

\subsubsection{Other Antimicrobial Peptides}

In addition to defensin antimicrobial peptides a large number of other peptides with antimicrobial activity have been identified in insects. It has just been in recent years that other types of antimicrobial peptides have been detected in ticks. Microplusin, a 10,204 Da polypeptide with six cysteine residues and no sequence similarity to any known molecule, was isolated from the hemolymph of Boophilus microplus (Fogaça et al., 2004). Expression of the microplusin gene was observed in the ovaries, fat body and hemocytes and the mature peptide appeared to be released into the hemolymph. Lai et al. (2004b) subsequently isolated an $11 \mathrm{kDa}$ antimicrobial protein, called hebraein, from the hemolymph of fed female Amblyomma hebraeum ticks. Hebraein is comprised of six cysteine residues and a histidinerich carboxyl-terminal region. Analysis reveals it has the same cysteine motif as microplusin, but microplusin only has four histidine residues near its carboxyl terminus. Alignment gives an identity of $62 \%$ and a similarity of $73 \%$ between microplusin and hebraein sequences suggesting they belong to the same protein family. Native and recombinant hebraein showed antimicrobial activity against Gram-positive Staphylococcus aureus, Gram-negative E. coli and the fungus Candida glabrato, clearly an antimicrobial peptide with widespread activity. Antifungal activity was greatly reduced in a histidine-deficient mutant indicating the histidine residues are important for antifungal activity. Fogaça et al. (2006) isolated a novel cysteine-rich antimicrobial peptide from the hemocytes of the cattle tick, Boophilus microplus. The peptide was named ixodidin and shown to inhibit the growth of E. coli and Micrococcus luteus. In addition, ixodidin exhibited proteolytic inhibitory activity against serine proteinases, the first report of a molecule from an arachnid that inhibits both bacterial growth and proteinase activity. Recently, Yu et al. (2005) identified a $2.8 \mathrm{kDa}$ peptide they named ixosin from the salivary glands of Ixodes sinensis. Ixosin is the first antimicrobial peptide lacking cysteine residues isolated from ticks and the purified ixosin displayed antimicrobial activity against Gram-positive and Gram-negative bacteria as well as fungi and low hemolytic activity. Arrieta et al. (2006) also reported that the eggs of the African cattle tick Amblyomma hebraeum had antibacterial activity against the Gram-negative bacteria, E. coli and Serratia marcescens. The substance was shown to be heat stable and cause lysis of bacterial cells. It was shown to be mainly in the egg wax and the Gene's organ was suggested as the source of the antibacterial substance. As we can see here the studies 
on tick antimicrobial substances reveal a number of unique peptides that make the understanding of the antimicrobial immune processes more complicated but also provide more opportunities for developing novel and effective antimicrobial agents.

\section{CONCLUSIONS}

Ticks as well as other invertebrates are able to protect themselves from invading parasites that enter the body cavity. The cuticle provides a first level protection as a mechanical and chemical barrier. Parasites that get past these barriers are then susceptible to attack by the phagocytic hemocytes if they are small such as bacteria or fungal spores. However, larger parasites are removed from circulation by nodule formation or encapsulation with numerous hemocytes. In addition, humoral responses protect the tick cells from infection by humoral encapsulation, hemagglutination and attach with antimicrobial proteins. Although there are slight differences in the soft and hard ticks, both groups show evidence of all the cellular and humoral immune responses discussed above. These responses occur in the hemocytes, hemolymph, gut lumen, salivary glands and fat body. During the past decade investigations on the innate immunity of ticks have increased but there still remains much to do in order to better understand the processes that prevent some parasites from surviving in ticks whereas other parasites are able to survive and be passed on to a host when the tick obtains a blood meal. Understanding these mechanisms is essential for the development of better strategies to control ticks and prevent the transmission of diseases by ticks.

The identification of the molecules involved in the various steps of the innate immune responses of ticks may also provide opportunities for the development of vaccines to prevent transmitted diseases from being spread. Investigations on the antimicrobial peptides of ticks may also result in the development of new substances such as novel antibiotics that can be used to treat diseases. Several cationic antimicrobial peptides of other invertebrates have completed phase III of clinical trials for topical and parenteral use in the treatment of systemic multi-resistant bacterial infections (Andrés and Dimarcq, 2005). Tick antimicrobial peptides show some unique characteristics such as constitutive expression and unique sequences that may make them good candidates for the development of new therapeutic drugs.

\section{REFERENCES}

Agarwala, K. L., S. Kawabata, M. Hirata, M. Miyagi, S. Tsunasawa and S. Iwanaga (1996) A cysteine protease inhibitor stored in the large granules of horseshoe crab hemocytes: purification, characterization, cDNA cloning, and tissue localization. Journal of Biochemistry, 119: 85-94.

Andrés, E. and J. L. Dimarcq (2005) Clinical development of antimicrobial peptides. International Journal of Antimicrobial Agents, 25: 448-449.

Arrieta, M. C., B. K. Leskiw and W. R. Kaufman (2006) Antimicrobial activity in the egg wax of the African cattle tick Amblyomma hebraeum (Acari: Ixodidae). Experimental and Applied Acarology, 39: 297-313.

Ashida, M., K. Kinoshita and P. Brey (1990) Studies on prophenoloxidase activation in the mosquito Aedes aegypti L. European Journal of Biochemistry, 188: 507-515.

Baldridge, G. D., T. J. Kurtti and U. G. Munderloh (2005) Susceptibility of Rickettsia monacensis and Rickettsia peacockii to Cecropin A, Ceratotoxin A, and lysozyme. Current Microbiology, 51: 233-238. 
Bangham, J., F. Jiffins and B. Lemaitre (2006) Insect immunity: the post-genomic era. Immunity, 25: 1-5.

Bázliková, M., J. Kazar and S. Schramek (1984) Phagocytosis of Coxiella burnetii by Hyalomma dromedarii tick haemocytes. Acta Virologica, 28: 48-52.

Boman, H. G. and D. Hultmark (1987) Cell-free immunity in insects. Annual Review of Microbiology, 41: $103-126$. Borovičková, B. and V. Hypša (2005) Ontogeny of tick hemocytes: a comparative analysis of Ixodes ricinus and Ornithodoros moubata. Experimental and Applied Acarology, 35: 317-333.

Brinton, L. P. and W. Burgdorfer (1971) Fine structure of normal hemocytes in Dermacentor andersoni Stiles (Acari: Ixodidae). Journal of Parasitology, 57: 1110-1127.

Bulet, P., C. Hetru, J. L. Dimarcq and D. Hoffman (1999) Antimicrobial peptides in insects; structure and function. Developmental and Comparative Immunology, 23: 329-344.

Bulet, P., R. Stocklin and L. Menin (2004) Anti-microbial peptides: from invertebrates to vertebrates. Immunological Reviews, 198: 169-184.

Bulet, P. and R. Stocklin (2005) Insect antimicrobial peptides: structures, properties and gene regulation. Protein and Peptide Letters, 12: 3-11.

Ceraul, S. M., D. E. Sonenshine and W. L. Hynes (2002) Resistance of the tick Dermacentor variabilis (Acari: Ixodidae) following challenge with the bacterium Escherichia coli (Enterobacteriales: Enterobacteriaceae). Journal of Medical Entomology, 39: 376-378.

Ceraul, S. M., D. E. Sonenshine, R. E. Ratzlaff and W. L. Hynes (2003) An arthropod defensin expressed by the hemocytes of the American dog tick, Dermacentor variabilis (Acari: Ixodidae). Insect Biochemistry and Molecular Biology, 33: 1099-1103.

Charlet, M., S. Chernysh, H. Philippe, C. Hetru, J. A. Hoffmann and P. Bulet (1996) Innate immunity. Isolation of several cysteine-rich antimicrobial peptides from the blood of a mollusk, Mytilus edulis. Journal of Biological Chemistry, 271: 21808-21813.

Cociancich, S., M. Goyffon, F. Bontems, P. Bulet, F. Bouet, A. Menez and J. Hoffmann (1993) Purification and characterization of a scorpion defensin, a $4 \mathrm{kDa}$ antibacterial peptide presenting structural similarities with insect defensins and scorpion toxins. Biochemical Biophysical Research Communications, 194: 17-22.

Eggenberger, L. R., W. J. Lamoreaux and L. B. Coons (1990) Hemocytic encapsulation of implants in the tick Dermacentor variabilis. Experimental and Applied Acarology, 9: 279-287.

Ehret-Sabatier, L., D. Loew, M. Goyffon, P. Fehlbaum, J. A. Hoffmann, A. van Dorsselaer and P. Bulet (1996) Characterization of novel cysteine-rich antimicrobial peptides from scorpion blood. Journal of Biological Chemistry, 271: 29537-29544.

Espagne, E., V. Douris, G. Lalmanach, B. Provost, L. Cattolico, J. Lesobre, S. Kurata, K. Iatrou, J. M. Drezen and E. Huguet (2005) A virus essential for insect host-parasite interactions encodes cystatins. Journal of Virology, 79: 9765-9776.

Fogaca, A. C., P. I. da Silva, Jr., M. Teresa, M. Miranda, A. G. Bianchi, A. Miranda, P. E. M. Ribolla and S. Daffre (1999) Antimicrobial activity of a bovine hemoglobin fragment in the tick Boophilus microplus. Journal of Biological Chemistry, 274: 25330-25334.

Fogaca, A. C., D. M. Lorenzini, L. M. Kaku, E. Esteves, P. Bulet and S. Daffre (2004) Cysteine-rich antimicrobial peptides of three cattle tick Boophilus microplus: isolation, structural characterization and tissue expression profile. Developmental and Comparative Immunology, 28: 191-200.

Fogaca, A. C., I. C. Almeida, M. N. Eberlin, A. S. Tanaka, P. Bulet and S. Daffre (2006) Ixodidin, a novel antimicrobial peptide from the hemocytes of the cattle tick Boophilus microplus with inhibitory activity against serine proteinases. Peptides, 27: 667-674.

Froidevaux, R., F. Krier, N. Nedjar-Arroume, D. Vercaigne-Marko, E. Kosciarz, C. Ruckebusch, P. Dhulster and D. Guillochon (2001) Antibacterial activity of a pepsin-derived bovine hemoglobin fragment. FEBS Letters, 491: 159-163.

Gillespie, J. P., M. R. Kanost and R. Trenczek (1997) Biological mediators of insect immunity. Annual Review of Entomology, 42: 611-643.

Goldstein, I. J., R. C. Hughes, M. Monsigny, T. Osawa and N. Sharon (1980) What should be called a lectin? Nature, 285: 66.

Götz, P. and H. G. Boman (1985) Insect Immunity. In: Compreshensive Insect Physiology, Biochemistry and 
Pharmocology, Vol. 3. (eds., Kerkut, G. A. and L. I. Gilbert), pp. 453-485, Pergamon Press, New York.

Götz, P. (1986) Encapsulation in Arthropods. In: Immunity in Invertebrates. (ed., Brehèlin, M.), pp. 153-170, Springer-Verlag, Berlin-Heidelberg.

Götz, P. and A. Vey (1986) Humoral encapsulation in insects. In: Hemocytic and Humoral Immunity in Arthropods. (ed. Gupta, A. P.), pp. 407-429, John Wiley and Sons, New York.

Gregorio, E. A. and N. A. Ratcliffe (1991) The phenoloxidase system and in vitro interaction of Trypanosoma rangeli with Rhodnius prolixus and Triatoma infestans hemolymph. Parasite Immunology, 13: 551-564.

Grubhoffer, L., J. Veres and F. Dusbabek (1991) Lectins as the molecular factors of recognition and defense reactions of ticks. In: Modern Acarology, vol. 2. (eds., Dusbabek, F. and V. Bukva), pp. 381-388, Praque and SPB Academic Publishing, The Hague.

Grubhoffer, L., V. Hypša and P. Volf (1997) Lectins (hemagglutinins) in the gut of the important disease vectors. Parasite, 4: 203-216.

Grubhoffer, L. and V. Kováŕ (1998) Arthropod lectins: affinity approaches in the analysis and preparation of carbohydrate binding proteins. In: Techniques in Insect Immunology FITC-5. (eds., Wiesner, A., G. G. Dunphy, V. J. Marmaras, I. Morishima, M. Sugumaran and M. Yamakawa), pp. 47-57, SOS Publications, Fair Haven, New Jersey.

Grubhoffer, L., V. Kovář and N. Rudenko (2004) Tick lectins: Structural and functional properties. Parasitology, 129: S113-S125.

Grunclová, L., H. Fouquier, V. Hypša and P. Kopáček (2003) Lysozyme from the gut of the soft tick Ornithodoros moubata: the sequence, phylogeny and post-feeding regulation. Developmental and Comparative Immunology, 27: $651-660$.

Gupta, A. P. (1991) Insect immunocytes and other hemocytes: roles in cellular and humoral immunity. In: Immunology of Insects and Other Arthropods (ed., Gupta, A. P.), pp. 19-118, CRC Press Inc., Boca Ratan.

Hoffman, D. and J. A. Hoffman (1990) Cellular and molecular aspects of insect immunity. Research in Immunology, 141: 895-896.

Hoffman, J. A., J. Reichhart and C. Hetru (1996) Innate immunity in higher insects. Current Opinion in Immunology, 8: 8-13.

Honey, K. and A. Y. Rudensky (2003) Lysosomal cysteine proteases regulate antigen presentation. Nature Reviews. Immunology, 3: 472-482.

Hubert, F., T. Noël and P. Roch (1996) A member of the arthropod defensin family from edible Mediterranean mussels (Mytilus galloprovincialis). European Journal of Biochemistry, 240: 302-306.

Hultmark, D. (1993) Immune reactions in Drosophila and other insects: a model for innate immunity. Trends in Genetics, 9: 178-183.

Hultmark, D. (1996) Insect lysozymes. In: Lysozymes: Model Enzymes in Biochemistry and Biology. (ed., Jollés, P.), pp. 87-102, Birkhauser Verlag, Basal, Switzerland.

Hynes, W. L., S. M. Ceraul, S. M. Todd, K. C. Seguin and D. E. Sonenshine (2005) A defensin-like gene expressed in the black-legged tick, Ixodes scapularis. Medical and Veterinary Entomology, 19: 339-344.

Imler, J. L. and P. Bulet (2005) Antimicrobial peptides in Drosophila: structures, activities and gene regulation. Chemical Immunology and Allergy, 86: 1-21.

Inoue, N., K. Hanada, N. Tsuji, I. Igarashi, H. Nagasawa, T. Mikami and K. Fujisaki (2001) Characterization of phagocytic hemocytes in Ornithodoros moubata (Acari: Ixodidae). Journal of Medical Entomology, 38: 514519.

Ivanov, V. T., A. A. Karelin, M. M. Philippova, I. V. Nazimov and V. Z. Plentnev (1997) Hemoglobin as a source of endogenous bioactive peptides: the concept of tissue-specific peptide pool. Biopolymers, 43: 171-188.

Iwanaga, S. (2002) The molecular basis of innate immunity in the horseshoe crab. Current Opinion in Immunology, 14: 87-95.

Johns, R., D. E. Sonenshine and W. L. Hynes (1998) Control of bacterial infections in the hard tick Dermacentor variabilis (Acari: Ixodidae): evidence for the existence of antimicrobial proteins in tick hemolymph. Journal of Medical Entomology, 35: 458-464.

Johns, R., D. E. Sonenshine and W. L. Hynes (2000) Response of the tick Dermacentor variabilis (Acari: Ixodidae) to hemocoelic inoculation of Borrelia burgdorferi (Spirochetales). Journal of Medical Entomology, 37: 265-270. 
Johns, R., J. Ohnishi, A. Broadwater, D. E. Sonenshine, A. M. De Silva and W. L. Hynes (2001a) Contrasts in tick innate immune responses to Borrelia burgdorferi challenge: immunotolerance in Ixodes scapularis versus immunocompetnece in Dermacentor variabilis (Acari: Ixodidae). Journal of Medical Entomology, 38: 99-107.

Johns, R., D. E. Sonenshine and W. L. Hynes (2001b) Identification of a defensin from the hemolymph of the American dog tick, Dermacentor variabilis. Insect Biochemistry and Molecular Biology, 31: 857-865.

Jollés, P. and J. Jollés (1984) What's new in lysozyme research? Always a model system, today as yesterday. Molecular and Cellular Biochemistry, 63: 165-189.

Joyce, J. A., A. Baruch, K. Chehade, N. Meyer-Morse, E. Giraudo, F. Y. Tsai, D. C. Greenbaum, J. H. Hager, M. Bogyo and D. Hanahan (2004) Cathepsin cysteine proteases are effectors of invasive growth and angiogenesis during multistage tumorigenesis. Cancer Cell, 5: 443-453.

Kaaya, G. P. (1993) Inducible humoral antibacterial immunity in insects. In: Insect Immunity. (ed., Pathak, J. P. N.), pp. 69-89, Kluwer Academic Publishers, Dordrecht, The Netherlands

Kadota, K., E. Satoh, M. Ochiai, N. Inoue, N. Tsuji, I. Igarashi, N. Nagasawa, T. Mikami, F. G. Claveria and K. Fujisaki (2002) Existence of phenol oxidase in the argasid tick Ornithodoros moubata. Parasitology Research, 88: 78-784.

Kadota, K, S. Walter, F. G. Claveria, I. Igarashi, D. Taylor and K. Fujisaki (2003) Morphological and populational characteristics of hemocytes of Ornithodoros moubata nymphs during the ecdysial phase. Journal of Medical Entomology, 40: 770-776.

Kamwendo, S. P., G. A. Ingram, F. L. Musisi and D. H. Molyneux (1993) Haemagglutinin activity in tick (Rhipicephalus appendiculatus) haemolymph and extracts of gut and salivary glands. Annals of Tropical Medicine and Parasitology, 87: 303-305.

Kamwendo, S. P., F. L. Musis, A. J. Trees and D. H. Molyneux (1995) Effect of haemagglutinin (lectin) inhibitory sugars in Theileria parva infection in Rhipicephalus appendiculatus. International Journal for Parasitology, 25: 29-35.

Karim, S., N. J. Miller, J. Valenzuela, J. R. Sauer and T. N. Mather (2005) RNAi-mediated gene silencing to assess the role of synaptobrevin and cystatin in tick blood feeding. Biochemical and Biophysical Research Communications, 334: 1336-1342.

Kopáček, P., R. Vogt, L. Jindrak, C. Weise and I. Safarik (1999) Purification and characterization of the lysozyme from the gut of the soft tick Ornithodoros moubata. Insect Biochemistry and Molecular Biology, 29: 989-997.

Kotsyfakis, M., A. Sá-Nunes, I. M. B. Francischetti, T. N. Mather, J. F. Andersen and J. M. C. Ribeiro (2006) Antiinflammatory and immunosuppressive activity of sialostatin L, a salivary cystatin from the tick Ixodes scapularis. Journal of Biological Chemistry, 281: 26298-26307.

Kovár, V., P. Kopáček and L. Grubhoffer (2000) Isolation and characterization of Dorin M, a lectin from plasma of the soft tick Ornithodoros moubata. Insect Biochemistry and Molecular Biology, 30: 195-205.

Kuhn, K. H. and T. Haug (1994) Ultrastructural, cytochemical, and immunocytochemical characterization of haemocytes of the hard tick Ixodes ricinus (Acari: Chelicerata). Cell and Tissue Research, 277: 493-504.

Kuhn, K. H., M. Rittig, T. Häupl and G. R. Burmester (1994) Haemocytes of the hard tick Ixodes ricinus express coiling phagocytosis of Borrelia burgdorferi. Developmental and Comparative Immunology, 18: S115.

Kuhn, K. H. (1996) Mitotic activity of the hemocytes in the tick Ixodes ricinus (Acari; Ixodidae). Parasitology Research, 82: 511-517.

Kuhn, K. H., J. Uhliŕ and L. Grubhoffer (1996) Ultrastructural localization of a sialic acid—specific hemolymph lectin in the hemocytes and other tissues of the hard tick Ixodes ricinus (Acari: Chelicerata). Parasitology Research, 82: 215-221.

Lackie, A. M. (1988) Immune mechanisms in insects. Parasitology Today, 4: 98-105.

Lai, R., L. O. Lomas, J. Jonczy, P. C. Turner and H. H. Rees (2004a) Two novel non-cationic defensin-like antimicrobial peptides from hemolymph of the female tick, Amblyomma hebraeum. Biochemistry Journal, 379: 681685.

Lai, R., H. Takeuchi, L. O. Lomas, J. Jonczy, D. J. Rigden, H. H. Rees and P. C. Turner (2004b) A new type of antimicrobial protein with multiple histidines from the hard tick, Amblyomma hebraeum. FASEB Journal, 18: 14471449.

Lehane, J. J., S. Aksoy and E. Levashina (2004) Immune responses and parasite transmission in blood-feeding 
insects. Trends in Parasitology, 20: 433-439.

Lima, C. A., S. D. Sasaki and A. S. Tanaka (2006) Bmcystatin, a cysteine proteinase inhibitor characterized from the tick Boophilus microplus. Biochemical and Biophysical Research Communications, 347: 44-50.

Lombardi, G., D. Burzyn, J. Mundinano, P. Berguer, P. Bekinschtein, H. Costa, L. F. Castillo, A. Goldman, R. Meiss, I. Piazzon and I. Nepomnaschy (2005) Cathepsin-L influences the expression of extracellular matrix in lymphoid organs and plays a role in the regulation of thymic output and of peripheral T cell number. Journal of Immunology, 174: 7022-7032.

Loosová, G., L. Jindrák and P. Kopáček (2001) Mortality caused by experimental infection with the yeast Candida haemulonii in the adults of Ornithodoros moubata (Acarina: Argasidae). Folia Parasitologia, 48: 49-53.

Machel, M. (1977) [Phagocytosis in Hyalomma dromedarii Koch ticks following intracoelomatic infection with Yersinia enterocolitica]. Wiadomości Parazytologiczne, 23: 31-33. (In Polish)

Martin, H. S., S. Timothy, S. Manickam, S. Kenneth and H. L. John (1995) Proenzyme of Manduca sexta phenoloxidase: purification, activation, substrate specificity of the active enzyme, and molecular cloning. Proceeding of the National Academy of Science, USA, 92: 7764-7768.

Matsuo, T., Y. Okoda, B. Badgar, N. Inoue, X. Xuan, D. Taylor and K. Fujisaki (2004) Fate of GFP-expressing Escherichia coli in the midgut and response to ingestion in a tick, Ornithodoros moubata (Acari: Argasidae). Experimental Parasitology, 108: 67-73.

Matsushita, M. (1996) The lectin pathway of the complement system. Microbiology and Immunology, 40: 887-893.

Matsushita, M., Y. Endo, M. Nonaka and T. Fujita (2001) Activation of the lectin complement pathway by ficolins. International Immunopharmacology, 1: 359-363.

Millar, D. A. and N. A. Ratcliffe (1994) Invertebrates. In: Immunology: A Comparative Approach. (ed. Turner, R. D.), pp. 29-68, Wiley, Chichester, England.

Munderloh, U. K. and T. J. Kurtti (1995) Cellular and molecular inter-relationships between ticks and prokaryotic tick-borne pathogens. Annual Review of Entomology, 40: 221-243.

Nakajima, Y., A. van der Goes van Naters-Yasui, D. Taylor and M. Yamakawa (2001) Two isoforms of a member of the arthropod defensin family from the soft tick, Ornithodoros moubata (Acari: Argasidae). Insect Biochemistry and Molecular Biology, 31: 747-751.

Nakajima, Y., D. Taylor and M. Yamakawa (2002a) Involvement of antibacterial peptide defensin in tick midgut defense. Experimental and Applied Acarology, 28: 135-140.

Nakajima, Y., A. van der Goes van Naters-Yasui, D. Taylor and M. Yamakawa (2002b) Anitbacterial peptide defensin is involved in midgut immunity of the soft tick, Ornithodoros moubata (Acari: Argasidae). Insect Molecular Biology, 11: 611-618.

Nakajima, Y., J. Ishibashi, F. Yukuhiro, A. Asaoka, D. Taylor and M. Yamakawa (2003a) Antibacterial activity and mechanism of action of tick defensin against Gram-positive bacteria. Biochimica et Biophysica Acta, 1624: 125130.

Nakajima, Y., K. Ogihara, D. Taylor and M. Yamakawa (2003b) Antibacterial hemoglobin fragments from the midgut of the soft tick, Ornithodoros moubata (Acari: Argasidae). Journal of Medical Entomology, 40: 78-81.

Nakajima, Y., H. Saido-Sakanaka, D. Taylor and M. Yamakawa (2003c) Up regulated humoral immune response in the soft tick, Ornithodoros moubata (Acari: Argasidae). Parasitology Research, 91: 476-481.

Nakajima, Y., H. Saido-Sakanaka, K. Ogihara, D. Taylor and M. Yamakawa (2005) Antibacterial peptides are secreted into the midgut lumen to provide antibacterial midgut defense in the soft tick, Ornithodoros moubata (Acari: Argasidae). Applied Entomology and Zoology, 40: 391-397.

Nomura, T. and N. Katunuma (2005) Involvement of cathepsins in the invasion, metastasis and proliferation of cancer cells. Journal of Medical Investigation, 52: 1-9.

Olafsen, J. A. (1986) Invertebrate lectins: biochemical heterogeneity as a possible key to their biological function. In: Immunity in Invertebrates (ed., Brehélin, M.), pp. 95-111, Springer Verlag, Berlin, Heidelberg.

Olafsen, J. A. (1996) Lectins: model of natural and induced molecules in invertebrates. In: Advances in Comparative and Environmental Physiology Vol. 24. (ed., Cooper, E. L.), pp. 49-76. Springer Verlag, Heidelberg.

Olsson, S. L., B. Ek and I. Bjork (1999) The affinity and kinetics of inhibition of cysteine proteinases by intact recombinant bovine cystatin C. Biochimica et Biophysica Acta, 1432: 73-81.

Otvos, L. Jr. (2000) Antibacterial peptides isolated from insects. Journal of Peptide Science, 6: 497-511. 
Parish, C. A., H. Jiang, Y. Tokiwa, N. Berova, K. Nakanishi, D. McCabe, W. Zuckerman, M. M. Xia and J. E. Gabay (2001) Broad-spectrum antimicrobial activity of hemoglobin. Bioorganic and Medicinal Chemistry, 9: 377-382.

Pathak, J. P. N. (1993) Cell-mediated Defence Reactions in Insects. In: Insect Immunity. (ed., Pathak, J. P. N.), pp. 47-58, Kluwer Academic Publishers, Dordrecht, The Netherlands.

Pereira, L. S., P. L. Oliveira, C. Barja-Fidalgo and S. Daffre (2001) Production of reactive oxygen species by hemocytes from the cattle tick Boophilus microplus. Experimental Parasitology, 99: 66-72.

Peumans, W. J. and E. J. M. van Damme (1995) Lectins as plant defense proteins. Plant Physiology, 109: 347-352.

Podboronov, V. M., V. M. Bondarenko and V. V. Evdokimov (1982) [Immune reactions of Ornithodoros papillipes ticks (Argasidae) to the administration of different microorganisms]. Parazitologiia, 16: 238-241. (In Russian)

Podboronov, V. M. (1991) Anitbacterial protective mechanisms of ixodioid ticks. In: Modern Acarology, 2. (eds., Dusbábek and V. Bukva), pp. 375-380, Academia, Praque.

Qasba, P. K. and S. Kumar (1997) Molecular divergence of lysozymes/and $\alpha$-lactalbumin. Critical Reviews in Biochemistry and Molecular Biology, 32: 255-306.

Ratcliffe, N. A. and A. F. Rowley (1979) Role of hemocytes in defense against biological agents. In: Development, Forms, Functions and Techniques: Insect Hemocytes. (ed., Gupta, A. P.), pp. 331-414, Cambridge University, Cambridge.

Ratcliffe, N. A. (1982) Cellular defense reactions of insects. In: Immune Reaction to Parasites. (ed., Frank, W.), pp. 233-244, Fischer, Stuttgart.

Ratcliffe, N. A., C. Leonhard and A. F. Rowley (1984) Prophenoloxidase activation: nonself recognition and cell cooperation in insect immunity. Science, 226: 557-559.

Ratcliffe, N. A. and A. F. Rowley (1987) Insect responses to parasites and other pathogens. In: Immune Responses in Parasitic Infections, Vol. 4. (ed,. Soulsby, E. J. L.), pp. 271-332, CRC Press Inc., Boca Raton.

Ratner, S. and S. B. Vinson (1983) Pagocytosis and encapsulation: Cellular immune responses in Arthropoda. American Zoologist, 23: 185-194.

Reddy, V. Y., Q. Y. Zhang and S. J. Weiss (1995) Pericellular mobilization of the tissue-destructive cysteine proteinases, cathepsins B, L, and S, by human monocyte-derived macrophages. Proceedings of the National Academy Science USA, 92: 3849-3853.

Rego, R. O. M., O. Hajdušek, V. Kovář, P. Kopáček, L. Grubhoffer, V. Hypša (2005) Molecular cloning and comparative analysis of fibrinogen-related proteins from the soft tick Ornithodoros moubata and the hard tick Ixodes ricinus. Insect Biochemistry and Molecular Biology, 35: 991-1004.

Rego, R. O. M., V. Kováŕ, P. Kopáček, C. Weise, P. Man, I. Sauman and L. Grubhoffer (2006) The tick plasma lectin, Dorin M, is a fibrinogen-related molecule. Insect Biochemistry and Molecular Biology, 36: 291-299.

Reinheckel, T., S. Hagemann, S. Dollwet-Mack, E. Martinez, T. Lohmuller, G. Zlatkovic, D. J. Tobin, N. MaasSzabowski and C. Peters (2005) The lysosomal cysteine protease cathepsin L regulates keratinocyte proliferation by control of growth factor recycling. Journal of Cell Science, 118: 3387-3395.

Rowley, A. F. and N. A. Ratcliffe (1981) Insects. In: Invertebrate Blood Cells, Vol. 2. (eds., Ratcliffe, N. A. and A. F. Rowley), pp. 421-488, Academic Press, New York.

Rudenko, N., M. Bolovchenko, M. J. Edwards and L. Grubhoffer (2005) Differential expression of Ixodes ricinus tick genes induced by blood feeding or Borrelia burgdorferi infection. Journal of Medical Entomology, 42: 3641.

Sadd, B. M. and P. Schmid-Hempel (2006) Insect immunity shows specificity in protection upon secondary pathogen exposure. Current Biology, 16: 1206-1210.

Saul, S. J. and M. Sugumaran (1987) Protease-mediated phenoloxidase activation in the hemolymph of the tobacco hornworm, Manduca sexta. Archives of Insect Biochemistry and Physiology, 5: 1-11.

Schierack, P., R. Lucius, B. Sonnenburg, K. Schilling and S. Hartmann (2003) Parasite-specific immunomodulatory functions of filarial cystatin. Infection and Immunity, 71: 2422-2429.

Schmid-Hempel, P. (2005) Evolutionary ecology of insect immune defenses. Annual Review of Entomology, 50: $529-551$.

Serveau-Avesque, C., M. F. Martino, V. Herve-Grepinet, E. Hazouard, F. Gauthier, E. Diot and G. Lalmanach (2006) Active cathepsins B, H, K, L and S in human inflammatory bronchoalveolar lavage fluids. Biology of the 
Cell, 98: 15-22.

Sforca, M. L., A. Machado, R. C. R. Figueredo, S. Oyama Jr., F. D. Silva, A. Miranda, S. Daffre, M. T. M. Miranda, A. Spisni and T. A. Pertinhez (2005) The micelle-bound structure of an antimicrobial peptide derived from the $\alpha$ chain of bovine hemoglobin isolated from the tick Boophilus microplus. Biochemistry, 44: 6440-6451.

Silva, S. B., G. Savastano and V. R. Bittencourt (2006) [Cellular types involved in the immune response of females engorged of Boophilus microplus inoculated with Metarhizium anisopliae and Penicillium sp.]. Revista Brasileira de Parasitologia Veterinária, 15: 128-131. (In Portuguese)

Simser, J. A., K. R. Macaluso, A. Mulenga and A. F. Azad (2004a) Immune-responsive lysozymes from hemocytes of the American dog tick, Dermacentor variabilis and an embryonic cell line of the Rocky Mountain wood tick, D. andersoni. Insect Biochemistry and Molecular Biology, 34: 1235-1246.

Simser, J. A., A. Mulenga, K. R. Macaluso and A. F. Azad (2004b) An immune responsive factor D-like serine proteinase homologue identified from the American dog tick, Dermacentor variabilis. Insect Molecular Biology, 13: $25-35$.

Söderhäll, K. and V. J. Smith (1986a) The prophenoloxidase activating system: The biochemistry of its activation and role in arthropod cellular immunity, with special reference to crustaceans. In: Immunity in invertebrates. (ed. Brehèlin, M.), pp. 208-223, Springer-Verlag, Berlin.

Söderhäll, K. and V. J. Smith (1986b) The prophenoloxidase activating cascade as a recognition and defence system in arthropods. In: Humoral and Cellular Immunity in Arthropods. (ed., Gupta, A. P.), pp. 251-285, John Wiley and Sons, New York.

Sonenshine, D. E. (1993) Biology of Ticks, 447 p., Oxford University Press, New York.

Sonenshine, D. E., S. M. Ceraul, W. L. Hynes, K. R. Macaluso and A. F. Azad (2002) Expression of defensin-like peptides in tick hemolymph and midgut in response to challenge with Borrelia burgdorferi, Escherichia coli and Bacillus subitilis. Experimental and Applied Acarology, 28: 127-134.

Sonenshine, D. E., W. L. Hynes, S. M. Ceraul, R. Mitchell and T. Benzine (2005) Host blood proteins and peptides in the midgut of the tick Dermacentor variabilis contribute to bacterial control. Experimental and Applied Acarology, 36: 207-223.

Turk, V. and W. Bode (1991) The cystatins: protein inhibitors of cysteine proteinases. FEBS Letters, 285: 213-219.

Uhlír, J., L. Grubhoffer, and P. Volf (1996) Novel agglutinin in the midgut of the tick Ixodes ricinus. Folia Parasitologica, 43: 233-239.

Valenzuela, J. G., I. M. Francischetti, V. M. Pham, M. K. Garfield, T. N. Mater and J. M. Ribeiro (2002) Exploring the sialome of the tick Ixodes scapularis. Journal of Experimental Biology, 205: 2843-2864.

van der Goes van Naters-Yasui, A., D. Taylor, T. Shono and M. Yamakawa (2000) Purification and partial amino acid sequence of antibacterial peptides from the hemolymph of the soft tick, Ornithodoros moubata (Acari: Argasidae). In: Proceedings of the 3rd International Conference on Ticks and Tick-borne Pathogens: Into the 21st Century (eds., Kazimirova, M., M. Labuda and P. A. Nuttall), pp. 189-194, Institute of Zoology, Slovak Academy of Sciences, Bratislava, Slovakia.

Vasta, G. R. and J. J. Marchalonis (1983) Humoral recognition factors in the arthropoda. The specificity of chelicerate serum lectins. American Zoology, 23: 157-171.

Vasta, G. R. and J. J. Marchalonis (1984) Summation: immunobiological significance of invertebrate lectins. Progress in Clinical Biological Research, 154: 177-191.

Vasta, G. R. (1991) The multiple biological roles of invertebrate lectins: their participation in nonself recognition mechanisms. In: Phylogenesis of Immune Functions (eds., Warr, G. W. and N. Cohen), pp. 183-199, CRC Press Inc., Boca Raton.

Vasta, G. R., H. Ahmed, N. E. Fink, M. R. Elola, A. G. Marsh, A. Snowden and E. W. Odom (1994) Animal lectins as self/non-self recognition molecules. Biochemical and genetic approaches to understanding their roles and evolution. Annals of the New York Academy of Sciences, 712: 55-73.

Vasta, G. R., M. S. Quesenberry, H. A. Ahmed and N. O'Leary (1999) C-type lectins and galectins mediate innate and adaptive immune functions: their roles in the complement activation pathway. Developmental Comparative Immunology, 23: 401-420.

Vereš, J. and L. Grubhoffer (1990) Detection and partial characterization of a new plasma lectin in the hemolymph of the tick Ornithodoros tartakovskyi. Microbios Letters, 45: 61-64. 
Vey, A. (1993) Humoral Encapsulation. In: Insect Immunity. (ed., Pathak, J. P. N.), pp. 47-58, Kluwer Academic Publishers, Dordrecht, The Netherlands.

Vilmos, P. and E. Kurucz (1998) Insect immunity: evolutionary roots of the mammalian innate immune system. Immunology Letters, 62: 59-66.

Wille, A., A. Gerber, A. Heimburg, A. Reisenauer, C. Peters, P. Saftig, T. Reinheckel, T. Welte and F. Buhling. (2004) Cathepsin L is involved in cathepsin D processing and regulation of apoptosis in A549 human lung epithelial cells. Biological Chemistry, 385: 665-670.

Yamamoto, Y., S. Watabe, T. Kageyama and S. Takahashi (1999) Purification and characterization of Bombyx cysteine proteinase specific inhibitors from the hemolymph of Bombyx mori. Archives of Insect Biochemistry and Physiology, 41: 119-129.

Yu, D., Z. Sheng, X. Xu, J. Li, H. Yang, Z. Liu, H. H. Rees and R. Lai (2005) A novel antimicrobial peptide from salivary glands of the hard tick, Ixodes sinensis. Peptides, 27: 31-35.

Zhioua, E., M. T. Yeh and R. A. LeBrun (1997) Assay for pheonloxidase activity in Amblyomma americanum, Dermacentor variabilis, and Ixodes scapularis. Journal of Parasitology, 83: 553-554.

Zhou, J., M. Ueda, R. Umemiya, B. Battsetseg, D. Boldbaatar, X. Xuan, K. Fujisaki (2006) A secreted cystatin from the tick Haemaphysalis longicornis and its distinct expression patterns in relation to innate immunity. Insect Biochemistry and Molecular Biology, 36: 527-535. 